\title{
Aspectos Sobre a Qualidade da Matéria-Prima de Doce de Leite e suas Implicações nas Propriedades Sensoriais do Produto: um Estudo em Aula Prática
}

\section{Aspects About the Quality of the Milk Raw Material and its Implications for the Product's Sensory Properties: a Study in Practical Class}

\author{
Camila Fernanda Alba*a; Gisele Karine Murador Villelaa; Samera Rafaela Bruzaroski ${ }^{\text {; }}$ Régia Patricia Saviani Trentin; Maria \\ Tereza Pereira Souza ${ }^{a}$; Ivana Stefanini Carneiro Scachettib; Elsa Helena Walter de Santana ${ }^{\text {a }}$, Joice Sifuentes dos Santos ${ }^{\mathrm{a}}$
aUNOPAR, Programa de Pós-graduação Stricto Sensu em Ciência e Tecnologia do Leite e Derivados. PR, Brasil.
bUniversidde Anhanguera de São Paulo, Programa de Pós-Graduação Stricto Sensu em Farmácia. SP, Brasil.
*E-mail: camila.alba95@gmail.com

\begin{abstract}
Resumo
O doce de leite é consumido em países do Mercosul e composto de água, proteínas, lipídeos, minerais e açúcar. A acidez titulável (AT) do leite, teor de lactose e de gordura alteram as características sensoriais e de coloração do produto. O objetivo foi evidenciar, em aula prática, a importância da qualidade da matéria-prima na elaboração do doce de leite. Os leites pasteurizados (integral, desnatado ou zero lactose) foram avaliados quanto a AT antes e após adição de ácido lático ou bicarbonato de sódio. Após, foi adicionado $20 \%$ de açúcar (seis formulações diferentes), seguido de aquecimento até o ponto final. Na avaliação dos produtos foi observada textura, coloração e grau de doçura (56 alunos). F1(controle) apresentou coloração caramelo média, textura lisa, sem grumos, e sabor doce característico. Em F2 havia um excesso de AT no leite, com doce de leite de uma tonalidade mais clara e granuloso. F3 foi elaborada com excesso de bicarbonato de sódio, produzindo um doce escuro, sem chegar ao ponto final, e sabor amargo. Em F4 foi utilizado creme de leite (17\% de gordura), com cor caramelo médio, liso e menos doce. Na F5 foi utilizado leite desnatado, produzindo um doce de leite caramelo médio, liso e sabor doce um pouco mais acentuado. Já F6 utilizou leite zero lactose, produzindo um doce de leite marrom escuro, firme, com grumos e doçura marcante. Esta aula prática evidenciou a importância da qualidade da matéria-prima para o doce de leite e trouxe a realidade das Indústrias beneficiadoras, que a recebem com qualidade variada.
\end{abstract}

Palavras-chave: Pós-Graduação. Leite e Derivados. Acidez.

\begin{abstract}
Dulce de leche is consumed in the Mercosul countries, and it is composed by water, proteins, lipids, minerals and sugar. Milk titratable acidity, lactose and fat contents change the product sensorial and color characteristic. The objective was to evidence, in a practical class, to Master level students, the importance of raw material in the dulce de leche manufacture. Pasteurized milk (whole, skimmed or lactose free) were evaluated for titratable acidity, before and after the lactic acid or sodium bicarbonate addition. Then, 20\% of sugar was added to the milk (six different formulations), and it was heated until dulce de leche final point. In the products evaluation, texture, coloration and sweetness degree were evaluated by 56 students. F1 (control) presented medium caramel color, smooth texture, and characteristic sweet flavor. F2 presented an excess of titratable acidity, with lighter and grainy dulce de leche. F3 was elaborated with sodium bicarbonate excess, producing a dark dulce de leche, without reaching the final point, and bitter taste. F4 was produced with cream (17\% fat), and presented a medium caramel color, smooth and less sweet. In F5 skimmed milk was used, resulting in a dulce de leche with medium caramel color, smooth and a slightly more pronounced sweet flavor. F6 was produced with lactose free milk, producing a dark brown dulce de leche, with lumps and marked sweetness. This practical class highlighted the importance of the raw material quality for dulce de leche production and brought the reality of the beneficiary industries, which receive raw materials of varying quality.
\end{abstract}

Keywords: Post Graduation. Milk and Derivatives. Titratable Acidity.

\section{Introdução}

A pós-graduação no Brasil foi formalmente implantada em 1965, com o Parecer $n^{\circ}$ 977/65 de 3 de dezembro de 1965 do Conselho Federal de Educação (CFE), emitido por Newton Lins Buarque Sucupira. Neste documento, o chamado "pai da pós-graduação" brasileira define as diferenças entre a pós-graduação lato sensu (que significa "em sentido amplo"), voltada para a especialização e aperfeiçoamento, com objetivo técnico profissional específico sem abranger o campo total do saber em que se insere a especialidade, e da pósgraduação stricto sensu (que significa "em sentido restrito", que define o sistema de cursos que se superpõe à graduação com objetivos mais amplos e aprofundados de formação científica ou cultural (BRASIL, 1965). A pós-graduação stricto sensu era, inicialmente, dividida em Mestrados e Doutorados Acadêmicos. O Mestrado Acadêmico tem como objetivo a formação do pesquisador e do docente para atuarem na Educação Superior e também na Educação Básica. Em 1998, através da Portaria no 080 de 16 de dezembro de 1998, foram criados os Mestrados Profissionais, mais voltados ao atendimento de demandas dos setores produtivos e de serviços (BRASIL, 1998).

A formação em nível de Mestrado Acadêmico pressupõe o cumprimento de créditos em disciplinas obrigatórias e optativas, definidas pelo Programa de Pós-Graduação, e a condução de um trabalho de pesquisa, conduzido a campo 
ou laboratório, finalizado pela Defesa da Dissertação de Mestrado. No curso de Mestrado em Ciência e Tecnologia de Leite e Derivados da Unopar, localizado em Londrina - PR, entre as disciplinas obrigatórias se encontra "Tecnologia de Leite e Derivados", que divide sua carga horária por meio de aulas teóricas e práticas, com objetivo de fornecer os subsídios necessários para a atuação dos Mestres egressos do Programa em Indústrias beneficiadoras de leite, entre outras colocações no mercado de trabalho.

O doce de leite, denominado na literatura internacional como "dulce de leche", é um produto lácteo tradicionalmente consumido em países do Mercosul, como Argentina, Uruguai e Brasil. O consumo ocorre, principalmente, como sobremesa, sozinho ou combinado com pães, bolachas, frutas e queijos. Também é um ingrediente bastante utilizado em produtos de confeitaria e na produção de sorvetes (DEMIATE; KONKEL; PEDROSO, 2001). A Legislação brasileira o define como "produto com ou sem adição de outras substâncias alimentícias, obtido por concentração e ação do calor a pressão normal ou reduzida do leite ou leite reconstituído, com ou sem adição de sólidos de origem láctea e/ ou creme e adicionado de sacarose (parcialmente substituída ou não por monossacarídeos e/ou outros dissacarídeos" (BRASIL, 1997).

É uma dispersão aquosa constituída, principalmente, por carboidratos (sacarose e lactose) e proteínas do leite. A composição do produto é de $30 \%$ de água (máximo), $5 \%$ de proteínas (mínimo), $2 \%$ a $6 \%$ de lipídeos, $2 \%$ de cinzas (máximo) e 70\% de açúcares (máximo), do qual $30 \%$ de sacarose (máximo) e o restante é a lactose do leite [4]. A concentração do doce de leite faz com que o produto tenha atividade de água reduzida, permitindo estocagem a temperatura ambiente (SILVA et al., 2015). O elevado teor de sólidos, por volta de 70\%, também promove um alto conteúdo energético, assim como um importante valor nutricional, pela concentração de minerais e proteínas.

O doce de leite apresenta coloração caramelo de intensidade variável, desde creme claro até marrom muito escuro, em função da intensidade das reações de Maillard e da caramelização (DEMIATE; KONKEL; PEDROSO, 2001). A Reação de Maillard é a principal reação envolvida, também conhecida como reação de escurecimento não enzimático. Esta reação ocorre entre um açúcar redutor e um aminoácido, quando submetidos ao aquecimento. Após uma série de reações são formadas as melanoidinas, substância de coloração escura (ARENA et al., 2017). Entre os aminoácidos mais suscetíveis a Reação de Maillard se encontra a lisina. O leite é um alimento rico em lisina, e esta reação promove perda de até 30\% deste aminoácido (PAVLOVIC et al., 1994).

Os ingredientes básicos para produção de leite são o próprio leite e a sacarose, normalmente, adicionada a $20 \%$ da formulação. Bicarbonato de sódio $\left(\mathrm{NaHCO}_{3}\right)$ e a enzima $\beta$-galactosidase (ou lactase) são considerados como coadjuvantes de produção (BRASIL, 1997).
O leite recebido pela Indústria de Laticínios, de acordo com a Instrução Normativa $n^{\circ} 76$ de 2018 (BRASIL, 2018a), deve apresentar acidez entre 0,14 e $0,180,14 \mathrm{~g} / 100 \mathrm{~mL}$ de ácido lático. No entanto, para aumentar a extensão da Reação de Maillard, desejável do ponto de vista sensorial visual, favorecida em pH entre 6 e 7 (FRANCISQUINI et al., 2017), e evitar a formação de grânulos em função da precipitação de proteínas após o aquecimento (PERRONE et al., 2012), a acidez deve ser diminuída para $0,13 \mathrm{~g} / 100 \mathrm{~mL}$ de ácido lático.

A $\beta$-galactosidase tem importante papel no controle da arenosidade do doce de leite, um importante defeito durante o armazenamento do produto, com formação de cristais perceptíveis ao paladar. Com a quebra da lactose em glicose e galactose, esse defeito pode ser evitado. Outra forma utilizada pela indústria para evitar a cristalização é o uso de microcristais de lactose (OLIVEIRA; PENNA; NEVAREZ, 2009).

Dessa forma, o objetivo da presente pesquisa foi evidenciar a importância da qualidade da matéria-prima na elaboração de doce de leite.

\section{Material e Métodos}

A elaboração das seis formulações (Tabela 1) de doce de leite foi realizada com leite integral ou desnatado pasteurizado (Volpato, Arapongas - PR), ou leite UHT semidesnatado zero lactose (Líder, Lobato - PR), açúcar refinado (União, Mossoró - RN), bicarbonato de sódio (Kinino, São José do Rio Preto $\mathrm{SP})$ e creme de leite UHT (Nestle, Araçatuba - SP).

Quadro 1 - Formulações de doce de leite.

\begin{tabular}{|c|c|c|c|c|c|c|}
\hline & \multicolumn{5}{|c|}{ Formulações } \\
\hline Ingredientes & F1 & F2 & F3 & F4 & F5 & F6 \\
\hline $\begin{array}{c}\text { Leite pasteurizado } \\
\text { integral (L) }\end{array}$ & 2 & 2 & 2 & 2 & - & - \\
\hline $\begin{array}{c}\text { Leite pasteurizado } \\
\text { desnatado (L) }\end{array}$ & - & - & - & - & 2 & - \\
\hline $\begin{array}{c}\text { Leite UHT inte- } \\
\text { gral zero lactose } \\
(\mathrm{L})\end{array}$ & - & - & - & - & - & 2 \\
\hline $\begin{array}{c}\text { Açúcar refinado } \\
(\%)\end{array}$ & 20 & 20 & 20 & 20 & 20 & 20 \\
\hline $\begin{array}{c}\text { Bicarbonato de } \\
\text { sódio (\%) }\end{array}$ & $0, \mathbf{0 5}$ & - & 0,20 & 0,05 & 0,05 & 0,05 \\
\hline $\begin{array}{c}\text { Ácido lático } 10 \% \\
\text { (mL) }\end{array}$ & - & 10 & - & - & - & - \\
\hline $\begin{array}{c}\text { Creme de leite } \\
(\%)\end{array}$ & - & - & - & 10 & - & - \\
\hline
\end{tabular}

Fonte: Dados da pesquisa.

Os leites utilizados foram avaliados quanto a acidez titulável através da titulação do leite (antes e após adição de bicarbonato de sódio ou ácido lático) com $\mathrm{NaOH} 0,1 \mathrm{~N}$ e fenolftaleína, até coloração rósea (BRASIL, 2018b).

Os ingredientes foram misturados em panela de inox com fundo triplo e levados ao aquecimento em fogão a 
aproximadamente $100^{\circ} \mathrm{C}$, sob agitação constante. $\mathrm{O}$ ponto final foi determinado através do teste do pingo do doce de leite em um copo de água (ao pingar uma gota do doce de leite em um copo da água, se este submergir sem se desmanchar, já está no ponto, aproximadamente $70^{\circ}$ Brix). As formulações foram distribuídas em potes de cerâmica até resfriamento.

A avaliação dos produtos foi realizada a partir da análise visual dos doces de leite, observando-se a textura do produto (arenosidade) e sua coloração, seguido de avaliação do sabor do produto, centrada no grau de doçura. Esta avaliação foi realizada nos anos de 2015 (5 indivíduos), 2016 (25), 2017 (13), 2018 (6) e 2019 (7), totalizando 56 alunos do Programa de Mestrado em Ciência e Tecnologia de Leite e Derivados da Universidade Pitágoras Unopar (Unopar), durante as atividades da disciplina de Tecnologia de Leite e Derivados.

Os resultados são apresentados de forma descritiva.

\section{Resultados e Discussão}

O leite bovino contém, em média, $87,1 \%$ de água, 4,0\% de gordura, $3,3 \%$ de proteína, $4,6 \%$ de lactose, $0,7 \%$ de cinzas e $0,3 \%$ de outras substâncias (WALSTRA; WOUTERS; GEURTS, 2006). O uso do leite para elaboração de um produto lácteo, como o doce de leite, permite a preservação do produto por longos períodos de armazenamento a temperatura ambiente, contribuindo para o consumo de um produto com maiores níveis de minerais e proteínas presentes nesta importante matéria-prima. Além disso, durante o armazenamento o produto não necessita da cadeia do frio.

A F1 foi elaborada como formulação controle, em que a acidez original do leite $(0,18 \mathrm{~g} / 100 \mathrm{~mL}$ de ácido lático) foi reduzida $(0,13 \mathrm{~g} / 100 \mathrm{~mL})$ com a adição de bicarbonato de sódio, conforme preconizado pelos protocolos de fabricação do produto. Foi possível observar o desenvolvimento de uma coloração caramelo média, com textura lisa, sem a presença de grumos, e sabor doce característico (Figura 1A).

Figura 1 - Formulações de doce de leite com diferentes qualidades de matérias-primas. A - Formulação 1; B - Formulação 2; C - Formulação 3; D - Formulação 4; E - Formulação 5; F - Formulação 6.
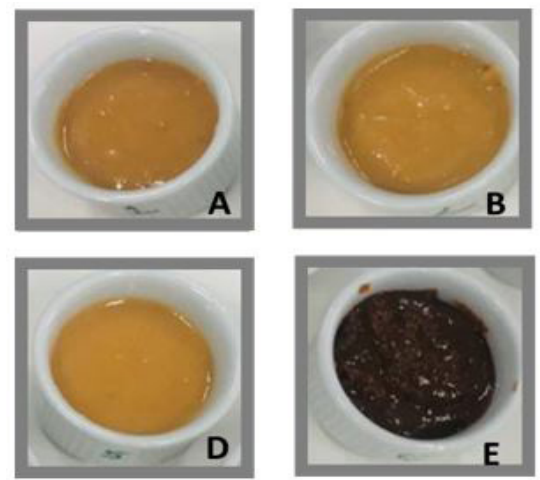

Fonte: dados da pesquisa.

Em F2 a acidez da matéria-prima não foi corrigida, e havia um excesso de acidez titulável no produto $(0,20 \mathrm{~g} / 100 \mathrm{~mL}$ de ácido lático). Não houve desenvolvimento da cor caramelo típica de doce de leite, apresentando uma tonalidade mais clara que a ideal (Figura 1B). Além do defeito na coloração do produto, o mesmo apresentava textura granulosa, semelhante ao doce talhado conhecido como ambrosia. A textura granulosa do produto foi decorrente da precipitação das proteínas do leite, favorecida pelo meio ácido após o aquecimento (WALSTRA; WOUTERS; GEURTS, 2006). O desenvolvimento da coloração do produto não ocorreu como desejado também em decorrência de menor acidez, uma vez que a reação de Maillard é favorecida em meio levemente básico (PERRONE et al., 2012).

F3 foi elaborada com excesso de bicarbonato de sódio $(0,20 \mathrm{~g} / 100 \mathrm{~g})$. Nesta formulação, a acidez titulável observada foi de $0,12 \mathrm{~g} / 100 \mathrm{~g}$ de ácido lático. Foi observada a formação de um doce de leite extremamente escuro, sem chegar ao ponto final de textura do produto, e com sabor amargo (Figura 1C). As características observadas nesta formulação foram originadas pelo excesso de bicarbonato. Em um meio altamente básico, a reação de Maillard é favorecida, havendo formação de quantidade excessiva de melanoidinas e consequente cor escura. Além disso, o bicarbonato de sódio, um ingrediente básico, possui sabor amargo, assim como também possuem sabor amargo alguns produtos da reação de Maillard (DAMODARAN; PARKIN; FENNEMA, 2010).

F4 foi elaborada utilizando-se creme de leite contendo $17 \%$ de gordura. A formulação apresentou coloração caramelo média, com textura lisa e sabor doce menos perceptível (Figura 1D). A adição de gordura proporciona menor percepção do sabor doce do produto. Ao ser utilizada uma matéria-prima com maiores teores de gordura (formulação final apresentava $4,5 \%$ de gordura), no processo industrial de elaboração de doce de leite se faz necessário o ajuste do teor de gordura. Este deve ser padronizado para $1,5 \%$ de gordura no leite, utilizando o quadrado de Pearson para o cálculo (PERRONE et al., 2012).

$\mathrm{Na}$ F5, a acidez também foi corrigida a $0,13 \mathrm{~g} / 100 \mathrm{~mL}$ de ácido lático. No entanto, foi utilizado leite desnatado. $\mathrm{O}$ produto obtido apresentou coloração caramelo média, com textura lisa e sabor doce um pouco mais acentuado que o normal (Figura 1E). A ausência de gordura no leite aumenta a percepção do gosto doce no doce de leite. Dessa forma, com o uso de um leite desnatado como matéria-prima, seria necessária a diminuição da quantidade de açúcar adicionada. No entanto, o uso de açúcar permite um melhor rendimento do produto.

Já F6 foi formulada utilizando-se leite zero lactose. O doce de leite apresentou cor marrom escura, com textura firme e presença de grumos e doçura marcante (Figura 1F). A produção do leite zero lactose envolve o uso de $\beta$-galactosidase, com o objetivo de clivar a lactose em seus monossacarídeos, glicose e galactose. A glicose é um dos açúcares redutores mais reativos na reação de Maillard (SHIBAO; BASTOS, 2011), levando esta formulação a uma excessiva coloração marrom. Além disso, a glicose apresenta maior grau de doçura do que 
a lactose, o que trouxe maior doçura final ao doce de leite produzido com esta matéria-prima.

\section{Conclusão}

As formulações elaboradas no presente trabalho apresentaram diferentes características no produto final. A execução desta atividade prática, por parte dos alunos, trouxe a realidade encontrada nas Indústrias beneficiadoras de leite, que recebem matéria-prima com qualidade variada. Foi possível evidenciar que a qualidade da matéria-prima é essencial para o desenvolvimento de um doce de leite com coloração caramelo característica, consistência cremosa, com aspecto liso uniforme e sabor doce característico, sem sabores e odores estranhos, conforme determina a legislação.

\section{Agradecimentos}

A participação de todos os Mestrandos envolvidos nas aulas práticas da disciplina de Tecnologia de Leite e Derivados, do Mestrado em Ciência e Tecnologia de Leite e Derivados. A Coordenação de Aperfeiçoamento de Pessoal de Nível Superior - Brasil (CAPES) - Código de Financiamento 001.

\section{Referências}

ARENA, S. et al. Dairy products and the Maillard reaction: A promising future for extensive food characterization by integrated proteomics studies. Food Chem., v.219, p.477-489, 2017. doi: 10.1016/j.foodchem.2016.09.165.

BRASIL. Parecer no 977/65, de 3 de dezembro de 1965.Brasília: MEC/CEF, 1965. Disponível em: <http://www.capes.gov.br/ capes>. Acesso em: 27 fev. 2020.

BRASIL. Ministério da Agricultura Pecuária e Abastecimento. Portaria No 354, de 4 de Setembro de 1997. Regulamento técnico para fixação de identidade e qualidade de doce de leite. Brasília: Ministério da Agricultura, 1997.

BRASIL. Ministério da Educação. Portaria n ${ }^{\circ}$ 080, de 16 de dezembro de 1998. Diário Oficial [da] República Federativa do
Brasil, seção 1, p.14, 11 janeiro de 1999. Brasília: DF, 1999.

BRASIL. Ministério da Agricultura, Pecuária e Abastecimento. Instrução normativa $\mathrm{n}^{\mathrm{o}}$ 76, de 26 de novembro de 2018. Regulamentos Técnicos que fixam a identidade e as características de qualidade que devem apresentar o leite cru refrigerado, o leite pasteurizado e o leite pasteurizado tipo A. Diário Oficial da União, Brasília, 2018a.

BRASIL. Ministério da Agricultura, Pecuária e Abastecimento. Manual de Métodos Oficais para Análise de Alimentos de Origem Animal. Secretaria de Defesa Agropecuária. - Brasília: MAPA, 2018 b.

DAMODARAN, S.; PARKIN, K.L.; FENNEMA, O.R. Química de Alimentos de Fennema. Porto Alegre: Artmed, 2010.

DEMIATE, I.M.; KONKEL, F.E.; PEDROSO, R.A. Avaliação da qualidade de amostras comerciais de doce de leite pastoso composição química. Ciênc. Tecnol. Aliment., v.21, n.1, p.108114, 2001. doi: 10.1590/S0101-20612001000100023.

FRANCISQUINI, J.D.F. et al. Reação de maillard: uma revisão. Rev. Inst. Laticínios Cândido Tostes., v.72, p.48-57, 2017. doi: 10.14295/2238-6416.v72i1.541.

OLIVEIRA, M.N.; PENNA, A.L.B.; NEVAREZ, H.G. Production of Evaporated Milk, Sweetened Condensed Milk and 'Dulce de Leche. In: TAMIME, A.Y. (Ed). Dairy Powders and Concentrated Products. Oxford: Blackwell Publishing, 2009. p.149-180.

PAVLOVIC, S.; SANTOS, R.C.; GLÓRIA, M.B.A. Maillard reaction during the processing of 'Doce de leite'. J. Sci. Food Agri., v.66, n.2, p.129-132,1994. doi: 10.1002/jsfa.2740660204.

PERRONE, Í.T. et al. Atributos tecnológicos de controle para produção do doce de leite. Rev. Inst. Laticínios Cândido Tostes., v.67, n.385, p.42-51, 2012. doi: 10.5935/2238-6416.20120022.

SHIBAO, J.; BASTOS, D.H.M. Produtos da reação de Maillard em alimentos: implicações para a saúde. Rev. Nutr., v.24, n.6, 2011. doi: 10.1590/S1415-52732011000600010.

SILVA, F.L. et al. Production of dulce de leche: The effect of starch addition. Food Sci. Technol., v.62, n.1, p.417-423, 2015. doi: 10.1016/j.lwt.2014.10.062.

WALSTRA, P.; WOUTERS, J.T.M.; GEURTS, T. Dairy Science and Technology. Boca Raton: CRC, 2006. 